Published in final edited form as:

J Psychopathol Behav Assess. 2016 June ; 38(2): 216-228. doi:10.1007/s10862-015-9515-9.

\title{
Parent Management of Organization, Time Management, and Planning Deficits among Adolescents with ADHD
}

\author{
Margaret H. Sibley ${ }^{1}$, Mileini Campez ${ }^{1}$, Analay Perez ${ }^{1}$, Anne S. Morrow ${ }^{1}$, Brittany M. Merrill ${ }^{1}$, \\ Amy R. Altszuler ${ }^{1}$, Stefany Coxe $^{1}$, and Carlos E. Yequez ${ }^{2}$ \\ ${ }^{1}$ Center for Children and Families, Florida International University, AHC 1 Room 146, 11200 SW \\ 8th Street, Miami, FL 33199, USA \\ ${ }^{2}$ University of Michigan, Ann Arbor, MI, USA
}

\begin{abstract}
Organization, Time Management, and Planning (OTP) problems are a key mechanism of academic failure for adolescents with ADHD. Parents may be well positioned to promote remediation of these deficits; yet, almost nothing is known about OTP management behaviors among parents of middle and high school students with ADHD. In a sample of 299 well-diagnosed adolescents with ADHD, a measure of parental OTP management was psychometrically validated. Latent Class Analysis was conducted to detect distinct patterns of parental OTP management and yielded four unique classes: Parental Control (18.7 \%), Parent-Teen Collaboration (20.4 \%), Homework Assistance (20.4\%), and Uninvolved (40.5\%). Logistic Regression analyses indicated that maladaptive parental OTP strategies were related to higher levels of parent and adolescent psychopathology. Parental OTP management did not relate to current adolescent OTP skills or GPA, indicating that parents did not select OTP management strategies in immediate response to adolescent functioning. Implications for parent-directed intervention are discussed.
\end{abstract}

\section{Keywords}

Parenting; ADHD; Adolescence; Executive functioning

It is well established that adolescents with Attention Deficit/Hyperactivity Disorder (ADHD) are at an elevated risk for academic failure (Barbaresi et al. 2007; Barkley et al. 2002; Kent et al. 2011) and by some estimates, over a third of these youth do not finish high school (Barkley et al. 2002). For teens with ADHD, high school dropout is seen as a steppingstone to established adult outcomes that include criminal activity, drug addiction, unemployment, and interpersonal problems (Kuriyan et al. 2013; Mannuzza et al. 2008; Molina et al. 2012). For example, adolescents with ADHD who have failing school grades are at highest risk for severe behavior problems and criminal activity by late adolescence (e.g., Molina et al. 2012).

Correspondence to: Margaret H. Sibley.

Conflict of Interest Margaret H. Sibley, Mileini Campez, Analay Perez, Anne S. Morrow, Brittany M. Merrill, Amy R. Altszuler, Stefany Coxe, and Carlos E. Yequez declare that they have no conflict of interest.

Experiment Participants All procedures were approved by the Institutional Review Board and APA ethical standards were followed. Informed parental consent and youth assent was obtained for all study participants. 
Similarly, adult educational and vocational outcomes are poorest for youth with ADHD who underachieve in high school (Kuriyan et al. 2013). In consideration of these risks, academic difficulties are the most common intervention target for teens with ADHD (Sibley et al. 2014c).

During middle and high school, executive functioning deficits (i.e., organization, time management, and planning problems; Barkley et al. 2001) are the most consistently identified mechanisms of ADHD-related academic failure (Langberg et al. 2013; Rogers et al. 2011; Sibley et al. 2014a). At the transition to middle school, the academic environment becomes increasingly complex as students must independently transition between classes with separate teachers, keep track of assigned work and deadlines, and complete multistep academic tasks and projects (Eccles 2004). Organization, time management, and planning (OTP) deficits become pernicious in secondary school, as older youth with ADHD struggle to master increased environmental demands with decreased teacher supervision (Benner and Graham 2009; Eccles 2004). Most teens with ADHD display OTP problems when managing school work (Sibley et al. 2014a, b, c), which manifest as disorganized materials, difficulty keeping track of assignments, poorly planned long-term projects, and trouble managing time during homework and other routine daily activities. Noticeably, the effect of these deficits on academics seems to vary (Kent et al. 2011) and can be debilitating for some, but not others (Barbaresi et al. 2007; Barkley et al. 2002). Outside of stimulant medication (Abikoff et al. 2009), little is known about factors that may attenuate the severity of adolescent OTP deficits, serving as key intervention mechanisms.

One potential intervention target may be parent promotion of OTP skills at home. A large portion of middle and high school students' academic work is completed outside of schoolincluding daily homework, studying for tests and quizzes, and completing long-term projects (Eccles 2004). Thus, parents are well positioned to reduce the effects of OTP deficits on schoolwork. Adolescent OTP strategies (i.e., writing down assignments in a daily planner, taking structured lecture notes, using a materials management system, pre-planning homework tasks, establishing a daily routine) can reduce academic impairment in teens with ADHD when monitored and reinforced by an adult (Evans et al. 2011; Langberg et al. 2012). Thus, parents of ADHD teens might be taught to apply behavior management principles to OTP skills-including clear expectations for behavior (i.e., requirements that adolescents utilize OTP strategies), monitoring adherence to these expectations (i.e., parental checks that strategies were used), and providing contingent reinforcement for performance (i.e., making privileges at home contingent upon adolescent use OTP strategies; Kazdin 2001). There is increasing evidence that secondary school staff lack the time and resources to careful supervise OTP interventions for adolescents with ADHD (Evans et al. 2007; Sibley et al. 2015b) and appropriate parental academic involvement benefits student performance across cultural contexts (Fan and Chen 2001; Hill and Tyson 2009; Jeynes 2007; Pomerantz et al. 2007). Thus, parental oversight of OTP skills could be key to offsetting the effects of these deficits.

Training in OTP management may be meaningful both to parents who utilize maladaptive management strategies and to those who refrain from OTP involvement altogether. Both parenting patterns may exacerbate youth OTP problems. For example, parents with their 
own ADHD symptoms may create a disorganized home environment (Nigg et al. 2004) that hinders adolescent OTP skill use. Psychopathology (e.g., depression, anxiety) is elevated among parents of ADHD youth and may lead to inconsistent or negative parenting (Burke et al. 2008; Chronis et al. 2003; Johnston and Mash 2001), preventing age-appropriate supervision and reinforcement of OTP skills. There is some evidence that parents of children with ADHD tend to be underinvolved in academics relative to the severity of their child's deficits (Rogers et al. 2009), despite documented benefits of parental academic support for ADHD youth (Hinshaw et al. 2000). Thus, some parents of adolescents with ADHD may avoid OTP involvement. Overall, almost nothing is known about parental OTP management in ADHD samples. A broader understanding of OTP-related parenting behavior may refine development of OTP interventions for adolescents with ADHD.

The current study investigated patterns of parental OTP management within a sample of adolescents with ADHD $(N=299)$. Study aims were to: (1) establish the psychometric properties of a measure of parental OTP management (Parent Academic Management Scale; PAMS), (2) identify distinct patterns of parental OTP support behaviors and (3) understand adolescent, parent, and family level predictors of these patterns. We hypothesized multiple classes of parental OTP involvement, both adaptive and maladaptive. We also hypothesized that maladaptive classes would be predicted by more severe adolescent symptoms, higher parental psychopathology, and known familial risk factors.

\section{Method}

\section{Participants}

Adolescents with DSM-IV-TR ADHD $(N=299)$ enrolled in one of four concurrent psychosocial treatment studies with a common battery at an ethnically diverse urban university clinic (Sibley et al. 2013, 2014a, b, c, 2015a, b). Participants were referred by their parents and schools and data were collected from parents, adolescents, and teachers at initial presentation to the research clinic. With the exception of participant grade requirements (e.g., middle vs. high school), study recruitment procedures, inclusion criteria, and diagnostic procedures were uniform. To participate in research, adolescents were required to: (a) meet DSM-IV-TR criteria for ADHD, (b) be enrolled in school, (c) have an estimated IQ > 80, and (d) have no history of an autism spectrum disorder. Table 1 provides demographic and clinical characteristics of the sample.

\section{Procedures}

For all potential participants, the primary caretaker was administered a brief phone screen containing the DSM-IV-TR ADHD symptoms and questions about impairment. Families were invited to an intake assessment to determine study eligibility if the parent endorsed on the phone screen: (1) a previous diagnosis of ADHD $\underline{\mathrm{OR}}$ four or more symptoms of either inattention or hyperactivity/impulsivity (H/I; APA, 2000) AND (2) clinically significant problems in daily life functioning (at least a " 3 " on a " 0 to 6" impairment scale; Fabiano et al. 2006). 
At the intake assessment, informed parental consent and youth assent were obtained and study eligibility was assessed. The primary caretaker participated in the assessment, and when available, other parents provided supplemental information. ADHD diagnosis was assessed through a combination of parent structured interview (Computerized-Diagnostic Interview Schedule for Children) and parent and teacher rating scales (Shaffer et al. 2000; Pelham et al. 1992) based on standard and recommended practice (Pelham et al. 2005). Additionally, the clinician administered a brief intelligence test (Wechsler Abbreviated Scale of Intelligence-II; Wechsler 2011a), achievement testing (Wechsler Individual Achievement Test-III, Wechsler 2011b) and a standard rating scale battery. These ratings included measures of adolescent and parent psychopathology, parent-teen interactions, adolescent academic functioning, and demographic information. Ratings were obtained directly from a core academic teacher who was identified by the parent or teen as teaching a class in which the adolescent experienced academic impairment. Cross-situational impairment was assessed for the purpose of ADHD diagnosis by examining parent and teacher impairment ratings and school grades obtained from official report cards. Impairment was defined as: (a) parent or teacher endorsement of academic impairment on an impairment rating scale (" 3 " or higher on a 7-point scale) or (b) impairment present in school grade book (e.g., failing to turn-in greater than $20 \%$ of assignments during the last month in at least one class or possessing a grade of $\mathrm{D}$ or $\mathrm{F}$ during the last month in at least one class). The academic characteristics of the sample are presented in Table 2. Dual clinician review was conducted by doctoral level psychologists to determine diagnosis and study eligibility. When disagreement occurred, a third psychologist was consulted. After intake, seven potential participants were excluded for the following reasons: IQ $<80(N=2)$, insufficient academic impairment $(N=4)$, and symptoms better explained by another mental disorder $(N=1)$.

\section{Measures}

Parental OTP Involvement-Parent-report of OTP skill monitoring, assistance, and reinforcement during the past week was measured using the PAMS. Parent-report of this construct was indicated due to the poor validity of self-report by adolescents with ADHD (Sibley et al. 2012, 2014a, b, c), who are the only other observers of parent OTP management. The PAMS is a 16-item checklist that was developed during psychosocial treatment trials for adolescents with ADHD to measure the frequency with which parents monitor (e.g., check to see if your child wrote in a daily planner), assist with (e.g., help your child organize school materials), and reinforce (e.g., use a home academic contract) a range of adolescent OTP skills. Adolescent OTP skills included on the PAMS reflect empirically supported strategies included in psychosocial interventions for teens with ADHD (Evans et al. 2011; Langberg et al. 2012). Parents indicated the number of days during the past school week ( 0 to 5$)$ that they performed each activity.

OTP Skills-The 17-item Academic Skills subscale of the teacher Adolescent Academic Problems Checklist (AAPC) measures adolescent use of secondary-school specific OTP skills and is validated for samples of adolescents with ADHD (Sibley et al. 2014a, b, c). The teacher AAPC subscales possess strong internal reliability and concurrent validity (Sibley et al. 2014a, b, c). The AAPC reliably detects effects in evaluations of psychosocial treatment 
(Sibley et al. 2013) for adolescents with ADHD and alpha on the Academic Skills subscale was 0.91 in the current study.

Grade Point Average (GPA)—Official report cards were obtained directly from the school district or from parents. GPA for each academic quarter was calculated by converting all core academic grades to a 4-point scale (i.e., $4.0=\mathrm{A}, 3.0=\mathrm{B}, 2.0=\mathrm{C}, 1.0=\mathrm{D}, 0.0=\mathrm{F}$ ). Grades were not weighted for class difficulty. GPA for the quarter in which the baseline assessment occurred was utilized in this study.

IQ-The Wechsler Abbreviated Scale of Intelligence, 2nd Edition (WASI-II; Wechsler 2011a) was administered to participants to estimate full scale IQ. The WASI-II is an individually administered test of intelligence that assesses verbal comprehension and perceptual reasoning abilities through four subtests: Block Design, Vocabulary, Similarities, and Matrix Reasoning. The WASI-II possesses excellent psychometric properties (Wechsler 2011a).

ADHD and Oppositional Defiant Disorder (ODD) Symptoms-Each participant's level of inattention, H/I, and ODD symptom severity in the home setting was measured using the parent version of the Disruptive Behavior Disorder Rating Scale (DBD; Pelham et al. 1992). The DBD is a DSM-IV symptom rating scale. Respondents rate symptoms of ADHD and ODD as not at all present (0), just a little (1), pretty much (2), or very much (3). To calculate an index of symptom severity the average level (0-3) of each item on the inattention, H/I, and ODD subscales was calculated for each participant. The DBD's psychometric properties are very good for child and adolescent samples, with evidence of distinct inattention and $\mathrm{H} / \mathrm{I}$ factors and internally consistent subscales (Pelham et al. 1992; Sibley et al. 2012). In the current sample, subscale alphas ranged from 0.81 to 0.89 .

Parenting Stress-Parent strain stemming from the parentadolescent relationship was measured by the 21-item Caregiver Strain Questionnaire (CSQ; Brannan et al. 1997). At baseline, the parent indicated how his/her teen's problems affected the parent and family over the past 4 weeks. Responses were scored on a 5-point scale ranging from not at all to very much a problem. The CSQ shows strong psychometric properties. Internal consistency is strong (Brannan et al. 1997) for three subscales (objective strain, internalized subjective strain, externalized subjective strain) and the measure correlates well with other measures of family functioning. In this study, the 11-item objective strain subscale was used as a measure of parenting stress. In the current sample, alpha for this subscale was 0.84 .

Parental ADHD—The Adult ADHD Self-Report Scale (ASRS; Adler et al. 2006) was used to measure parent ADHD severity. Parents completed the ASRS at baseline. The ASRS is an 18 -item measure that contains adult-specific symptoms of ADHD. Each symptom is measured on a five-point scale $(0=$ Never to $4=$ Very Often). Respondents are asked to rate the presence of each symptom during the past 6 months. The ASRS self-report rating scale correlates highly with clinician ratings of ADHD and displays strong internal consistency $($ alpha $=0.88$; Adler et al. 2006). ADHD severity was calculated for each parent by calculating the mean ASRS item score. In the current study, alpha for the ASRS was 0.79. 
Parental Psychopathology-The Symptom Checklist-90-Revised (SCL-90-R; Derogatis 1996) was used to measure parent psychopathology. Parents completed the checklist at baseline. The SCL-90-R is a 90-item scale that measures nine symptom domains and three global indices using a five-point Likert scale. The SCL-90-R has good internal consistency on each subscale and possesses convergent, discriminant and predictive validity (Derogatis 1996, 1977). In this study, the Depression (DEP), Anxiety (ANX), Somatization (SOM), Global Severity Index (GSI), and Positive Symptom Distress Index (PSDI) subscales were included. GSI measures overall psychological distress and PSDI measures overall symptom intensity and is considered an index of response style (symptom minimization vs. exaggeration).

Adolescent Internalizing Problems-The Youth Self Report (YSR; Achenbach 1991) is a self-report measure of child and adolescent behavioral and emotional problems. The YSR contains 118 problem items rated on a $0-2$ scale and produces a range of broadband and narrowband subscales. The YSR possesses strong internal consistency and concurrent validity (Achenbach 1991). In the current study, the Anxious/Depressed and Withdrawn/ Depressed subscales were employed as measures of comorbid youth internalizing problems. The decision to use self, rather than parent, report of difficulties was based on research suggestion the superiority of youth report for internalizing problems (Bird et al. 1992).

\section{Analytic Plan}

Analyses were conducted with MPlus 6.12 (Múthen \& Múthen 1998-2010) or SPSS 22.

Exploratory Factor Analysis-An Exploratory Factor Analysis (EFA) was conducted to investigate the scale's underlying factor structure. Analyses were conducted in SPSS using oblique Promax rotation. Scree plots and initial eigenvalues were inspected for each solution and interpreted using standard guidelines (Costello and Osborne 2005). Structure coefficient loadings were inspected for the statistically optimal factorial solution and a coefficient of 0.40 was considered to be practically significant based on sample-size specific recommendations (Velicer and Fava 1998). In cases where items cross-loaded on factors, the highest loading was used to determine factor membership.

Internal Reliability-Cronbach's alpha was calculated for each factor and the entire scale. In cases of unacceptable internal consistency, correlations were examined between each item and the corresponding factor score to identify sources of poor internal consistency.

Latent Class Analyses-To identify distinct patterns of academic involvement among parents of adolescents with ADHD, Latent Class Analysis (LCA; McCutcheon 1987) was conducted. Prior to analyses, the 16 PAMS items were visually inspected to confirm that each conformed to the ordinal multinomial distribution on which the response scale was based. Upon inspection, seven items (\#1, \#8, \#9, \#10,\#11, \#13, \#16) were recategorized dichotomously (yes vs. no), due to high levels of endorsement at either of the scale endpoints suggesting that the distributions were better represented binomially. Latent classes were derived from the 16 PAMS items and modeled using proportional odds specification and a Maximum Likelihood (ML) estimator with robust standard errors. 
Four nested latent class models were estimated to represent two-, three-, four-, and five-class solutions. A six-class solution was not estimated because this model was underidentified. The relative fit of each model was compared by examination of multiple fit indices, as is standard and recommended practice (Collins and Lanza 2010). For each model, the bivariate chi-square overall test of model fit (Múthen \& Múthen 1998-2010), Bayesian Information Criterion (BIC), adjusted BIC (ABIC), and entropy were compared to select a model with optimized fit and parsimony. In cases of disagreement between fit indices, the most theoretically interpretable model was selected (Collins and Lanza 2010). To understand the characteristics of each latent class represented in the optimal solution, conditional probabilities for each item response were inspected. Names for each class were assigned on the basis of class composition.

Class Differences on PAMS Subscales, OTP Skills, and GPA-To further characterize latent classes, means and standard deviations for each PAMS subscale, OTP skills, and GPA are presented for each latent class. One-way ANOVAs with post-hoc paired comparisons were conducted to determine significant group differences on each construct. The Benjamini-Hochberg procedure was applied to account for multiple comparisons (Benjamini and Hochberg 1995) with the false discovery rate restricted to 0.05 .

Predictors of Latent Class Membership-To identify parent, family, and adolescent characteristics associated with the latent parenting classes, a multinomial logistic regression analysis using a robust Maximum Likelihood estimator (Huber/White; Huber 1967; White 1980) and a logit link function was conducted with the most populated class (class 4 , see Results) serving as the reference category. Parents were assigned a categorical variable classification based on their most likely class membership. ${ }^{1}$ Prior to this analysis, we tested whether mother and father figures differed in their latent class membership and found no significant difference $(p=0.87)$; therefore, both mother and father caretakers were included in the model. Six adolescent characteristics (age, sex, IQ, inattention, H/I, ODD), three family characteristics (ethnicity, number of children, marital status) and three parent characteristics (education level, parenting stress, parent ADHD) were entered as model predictors. Monte Carlo integration was employed to address missing values and retain all cases in this analysis.

We also conducted a secondary regression analysis $(N=128)$, which included members of the sample who were administered an extended battery of parent and youth psychopathology measures (i.e., the SCL-90, CBCL, and YSR). In this model, significant predictors of class membership in our first regression model were entered as covariates at step 1. At step 2, two adolescent symptom indices (anxious/depressed, withdrawn/depressed) and five parent SCL-90-R symptom indices (DEP, ANX, SOM, GSI, and PSDI) were entered as model predictors.

\footnotetext{
${ }^{1}$ Classification confidence was high with all classification probabilities in the LCA exceeding $95 \%$.
} 


\section{Results}

Exploratory Factor Analysis-Initial eigenvalues and scree plot examination for the PAMS suggested a three-factor solution $($ EEVA1 $=6.67$, EEVA2 $=1.60$, EEVA3 $=1.01)$. Examination of factor loadings for the three-factor solution (see Table 3) suggested that Factor 1 represented an OTP oversight factor consisting of 8 items that described parent assistance with and monitoring of specific OTP skills. Factor 2 contained five items that appeared to represent a contingency management factor, with items relating both to explicit documentation of behavioral expectations (i.e., use of checklists and calendars) and use of rewards and consequences to reinforce these expectations. Factor 3 appeared to represent a parental intrusion factor containing three items: communicating with teachers, checking the online grade portal, and doing homework for the adolescent. Cross-loadings were infrequent and modest (see Table 3).

Internal Reliability-Total score alpha was strong for the PAMS (0.90). Internal consistency was acceptable for Factor 1 (OTP oversight; alpha $=0.91$ ) and Factor 2 (contingency management; alpha $=0.78$ ). Alpha was unacceptable for Factor 3 (parental intrusion; alpha $=0.49$ ). After examining correlations between each item and the factor (see Table 3), the decision was made to examine each Factor 3 item separately in subsequent analysis.

Latent Class Analyses-Examination of model fit indices (see Table 4) and latent class structures of each solution indicated that a four-class solution optimized fit, parsimony, and theoretical clarity. Chi-square and relative entropy estimates indicated that all four models possessed adequate fit. According to the BIC, the three-class solution was optimal; however, according to the ABIC, the five-class solution was optimal. Inspection of the five-class solution revealed indistinct overlap amongst classes. However, the four-class solution offered clearly distinct classes that appeared consistent with existing theory. As a result, the four-class solution for parent OTP management was believed to optimize fit, parsimony, and theoretical clarity, as is recommended in the selection of latent class structure (Collins and Lanza 2010).

Item-level conditional probabilities for the four-class solution are presented in Table 5. Class 1 (Parental Control; $18.7 \%$ ) was characterized by high frequency parental involvement in all OTP activities. Parents in class 1 reported the highest levels of daily monitoring and assisting for the full range of OTP activities. They reported issuing rewards and consequences in reaction to academic performance, but were less likely than class 2 (see below) to do so through use of a contract with the adolescent. Class 2 (Parent-Teen Collaboration; $20.4 \%$ ) was the group most likely to set OTP expectations collaboratively with the adolescent (e.g., make a checklist) and use collaborative contingency management (e.g., use a contract with the adolescent) to reinforce OTP skills. Class 2 relied on lower levels of teacher communication and direct monitoring than class 1 and provided lower levels of direct homework assistance than classes 1 and 3. Class 3 (Homework Assistance; $20.4 \%$ ) frequently monitored and assisted with homework and was the class most likely to do some of the adolescent's homework for him/her (see Table 5). However, these parents 
refrained from involvement in additional OTP activities such as monitoring a daily planner or materials organization system or using contingencies to reinforce skills. Finally, class 4 (Uninvolved; $40.5 \%$ ) was the most populated class, with parents reporting very low OTP involvement across domains.

Class Differences on PAMS Subscales, OTP Skills, and GPA—Results (see Table 6) indicated that all classes were significantly different on all five indices of OTP involvement with a few exceptions: class 1 (Parental Control) and class 2 (Parent-Teen Collaboration) did not differ on overall use of contingency management, frequency of grade portal checking, or doing homework for the teen; class 1 and class 3 (Homework Assistance) did not differ on doing homework for the teen; class 2 and class 3 did not differ on OTP oversight, teacher communication, or checking the grade portal; class 2 and class 4 did not differ on doing homework for the teen; and class 3 and class 4 (uninvolved) did not differ on use of contingency management. No groups differed on teacher rated OTP skill use or GPA (see Table 6).

\section{Predictors of Latent Class Membership}

Model results (see Table 7) indicated that compared to class 4 (Uninvolved), members of class 1 (Parental Control) were significantly more likely to have adolescents who were a younger age $(b=-0.30, S E=0.14, p=0.03, O R=0.74)$, with a lower IQ $(b=-0.05, S E=$ $0.02, p=0.01, O R=0.95)$ and less severe ODD symptoms $(b=-0.15, S E=0.08, p=0.05$, $O R=0.86$ ). Members of class 2 (Parent-Teen Collaboration) did not significantly differ from members of class 4 (Uninvolved) on any predictors. Members of class 3 (Homework Assistance) were significantly more likely than members of class 4 to have adolescents who were a younger age $(b=-0.67, S E=0.18, p<0.01, O R=0.51)$, female $(b=-0.80, S E=$ $0.40, p=0.05, O R=0.45)$, and possessed more severe inattention $(b=0.76, S E=0.34, p=$ $0.02, O R=2.14)$, but lower $\mathrm{H} / \mathrm{I}$ severity $(\mathrm{b}=-0.66, S E=0.30, p=0.03, O R=0.52)$.

For Model 2, age, sex, IQ, inattention, H/I, and ODD severity were entered into the model as covariates, based on the results of Model 1 . The overall model was significant $\left[\chi^{2}(39)=\right.$ $60.03, p=0.017]$. Results (see Table 8 ) indicated that after controlling for covariates, compared to class 4 (Uninvolved), class 1 (Parental Control) was significantly less likely to experience symptoms of depression $(b=-0.10, S E=0.05, p=0.05, O R=0.90)$ and more likely to experience somatic complaints $(b=0.10, S E=0.05, p=0.04, O R=1.11)$. Members of class 2 (Parent-Teen Collaborative) possessed a lower symptom exaggeration ( $b$ $=-0.09, S E=0.04, p=0.04, O R=0.92)$ than members of class 4 (Uninvolved). Members of class 3 (Homework Assistance) were significantly more likely than members of class 4 to have adolescents with higher levels of withdrawn/depressed symptoms ( $b=0.18, S E=0.07$, $p=0.02, O R=1.19)$ but lower levels of anxious/depressed symptoms $(b=-0.15, S E=0.06$, $p=0.01, O R=0.86)$. Homework Assistance parents also reported higher global symptom severity $(b=0.20, S E=0.09, p=0.03, O R=1.22)$ and lower symptom exaggeration $(b=$ $-0.12, S E=0.05, p=0.02, O R=0.89)$ than Uninvolved parents. 


\section{Discussion}

The purpose of this study was to characterize parental OTP management in a sample of adolescents with ADHD. After assuring that our parent report measure (PAMS) possessed adequate psychometric properties, findings were as follows: (1) most parents $(59.5 \%)$ displayed one of three distinct OTP management strategies (Parental Control, Parent-Teen Collaboration, Homework Assistance), with the remaining minority (40.5\%) displaying an Uninvolved pattern; (2) current adolescent OTP skills, academic functioning, and familial context did not influence a parent's OTP management strategy; and (3) distinct parent and adolescent characteristics reliably predicted class membership. We discuss each finding below.

In our sample, a majority of parents reported consistent attempts to manage the OTP problems of adolescents with ADHD. Parents who used a Parental Control strategy (18.7\%) reported the most frequent level of monitoring of and assistance with OTP activities, and frequently issued rewards and consequences in response to adolescent performance (see Table 5). By contrast, parents who used the Parent-Teen Collaboration strategy (20.4\%) provided a lower level of monitoring and assistance than the Parental Control style, but were more likely to rely on parent-teen collaborative strategies such as cooperatively contracting and creating checklists to promote independent skill use. Some parents also reported a Homework Assistance style (20.4\%) in which monitoring and assistance was provided, but restricted to homework completion, rather than the full range of OTP activities (e.g., writing in a daily planner, keeping materials organized, taking notes in class). Like the Parental Control group, the Homework Assistance group reported doing homework for the adolescent at least once a week (see Table 6).

Familial context (i.e., single parent, ethnicity, number of children), adolescent OTP problems, and GPA were not related to a parent's OTP management strategy. This is consistent with research suggesting that parenting styles transcend family characteristics (Darling 1999; Jeynes 2007). It also suggests that parents did not select OTP management strategies in response to their adolescent's current OTP skillset or school grades (see Table 6). However, future work is needed to fully understand longitudinal associations between adolescent OTP skills, parent OTP management style, and adolescent academic performance. For example, past academic failure may be more relevant than current functioning in determining a parent's selected OTP support strategy. In addition, strategies that create short term GPA increases (i.e., excessive parental assistance) may do so at a cost to long-term OTP skill development and academic independence.

Prediction models offered a preliminary profile of parents and adolescents in each class. The Parental Control class was predicted by lower adolescent IQ, younger age, and lower level of ODD, as well as higher parental somatization. Thus, the Parental Control strategy was most common with younger, lower functioning adolescents who displayed the highest levels of compliance (see Table 7). High parent somatization in this group may be a manifestation of high parental anxiety-parents in this sample were highly Hispanic and female (see Table 1), which is a population at risk for manifesting anxiety through somatic complaints, rather than traditional cognitive symptoms (Escobar et al. 1989). It is worth noting that the Parental 
Control class was also the only class to display PSDI (symptom exaggeration) scores that were equivalently high to the Uninvolved class (see Table 8). This finding may suggest a tendency for this class to pervasively exaggerate rating scale responses-including support behaviors on the PAMS. Alternatively, these parents may possess exaggerated perceptions of problem severity, leading them to view the adolescent as unable to apply OTP skills independently, needing excessive adult assistance.

Parents in the Parent-Teen Collaboration class were the least likely to possess elevated parent or adolescent psycho-pathology and were unlikely to exaggerate symptoms (PSDI). Across adolescent parenting domains, autonomy support strategies are recommended and emphasize accountability for independent completion of age appropriate tasks, rather than direct assistance (Pomerantz et al. 2007; Steinberg et al. 1992). Parent-Teen Collaboration is the OTP management strategy that appears most consistent with an autonomy support approach. Thus, it is not surprising that psychopathology and symptom exaggeration are lowest in these families (see Tables 7 and 8), who demonstrate general adaptive functioning.

The Homework Assistance class was predicted by young age, female sex, high inattention and depression severity, and low $\mathrm{H} / \mathrm{I}$ and anxiety severity (see Tables 7 and 8). Adolescents who display high levels of inattention and depressive symptoms, such as anhedonia and apathy toward schoolwork (Fröjd et al. 2008), may have parents who feel compelled to provide high levels of homework assistance. Similarly, atypically low levels of H/I may be related to a sluggish cognitive profile (Milich et al. 2001) and low levels of anxiety may lead an adolescent to show low homework approach behaviors, lacking concern for natural consequences of failure. These symptoms also may reduce homework productivity and compel parents to display high levels of homework assistance. Overall, global psychopathology was highest among these parents, who were most likely to do assignments for the adolescent and refrain from OTP involvement, except to provide assistance during homework time.

The failure of many parents to intervene (40.5\%), despite pressing adolescent OTP problems (see Table 6), is consistent with generally poor behavioral monitoring by parents of youth with ADHD (Murray and Johnston 2006). Poor parental monitoring and accountability is problematic in adolescence, as these constructs are proximal correlates of serious teen risk behaviors (Unnever et al. 2003). Our prediction models indicated that the Uninvolved group displayed the highest level of ODD symptoms (see Table 7), which supports a profile characterized by escalating adolescent behavior and reduced parental monitoring. Adolescents in this group also tended to possess the oldest ages (see Table 7), which may suggest that parents of older adolescents are less likely to provide OTP support, even in the presence of continued OTP deficits and academic problems (see Table 6). This finding is consistent with the developmental literature, which suggests that parents of typical adolescents reduce school involvement as adolescents age (Eccles and Harold 1993).

One limitation of this study is its cross-sectional design, which prevents understanding of causal relationships between parent OTP management style and predictors identified in our analyses. Second, we were unable to measure the implementation quality of parent OTP management strategies, and so our analyses relied on frequency of strategy use. We may 
have oversampled parents who demonstrate OTP involvement because our treatment study required parent participation. We also did not have comparison data for normative OTP involvement among middle and high school parents; however, since most students do not possess OTP deficits, it is unclear whether typical parents would intervene in this domain. Finally, we know of no gold standard criterion against which to judge the PAMS validity. Future psychometric evaluations of this scale should seek to provide additional evidence on the content and convergent validity of this scale. Future research on parent OTP management among adolescents with ADHD should utilize data collected longitudinally and consider comparison to parents of typically developing youth.

Despite its limitations, this study offered an important first look at OTP management among parents of adolescents with ADHD. Evidence suggested that a majority (59.5\%) of parents made consistent attempts monitor, assist with, and/or reinforce OTP related activities. Among involved parents, both adaptive and potentially maladaptive strategies were implemented. Thus, a majority of parents of adolescents with ADHD might benefit from training in age-appropriate OTP management to increase overall involvement $(40.5 \%)$ or replace maladaptive strategies $(39.1 \%)$ with age-appropriate ones (i.e., parent-teen collaboration). Such an intervention may require tailored components to address the unique parental OTP management profiles detected in this study, and should consider parent and youth psychological characteristics that may contribute to parental OTP management. Our ongoing work to develop a parent-involved intervention (Sibley et al. 2015a) shows promise of improving adolescent ADHD symptoms and academic functioning, as well as parent use of age-appropriate monitoring and rewards-based contingencies (Sibley et al. 2015a).

\section{Acknowledgments}

This project was supported by R34 MH092466 from the National Institute of Mental Health and R324A120169 from the Institute of Education Sciences. Partial support was also provided by the Klingenstein Third Generation Foundation fellowship in ADHD awarded to the first author.

\section{References}

Abikoff H, Nissley-Tsiopinis J, Gallagher R, Zambenedetti M, Seyffert M, Boorady R, McCarthy J. Effects of MPH-OROS on the organizational, time management, and planning behaviors of children with ADHD. Journal of the American Academy of Child \& Adolescent Psychiatry. 2009; 48:166175. [PubMed: 19127171]

Achenbach, TM. Manual for the youth self-report and 1991 profile. Burlington: Department of Psychiatry, University of Vermont; 1991.

Achenbach, TM. The Achenbach System of Empirically Based Assessemnt (ASEBA): Development, Findings, Theory, and Applications. Burlington, VT: University of Vermont Research Center for Children, Youth, \& Families; 2009.

Adler LA, Spencer T, Faraone SV, Kessler RC, Howes MJ, Biederman J, Secnik K. Validity of pilot adult ADHD self-report scale (ASRS) to rate adult ADHD symptoms. Annals of Clinical Psychiatry. 2006; 18:145-148. [PubMed: 16923651]

Barbaresi W, Katusic S, Colligan R, Weaver A, Jacobsen S. Long-term school outcomes for children with attention-deficit/hyperactivity disorder: a population-based perspective. Journal of Developmental and Behavioral Pediatrics. 2007; 28:265-273. [PubMed: 17700078]

Barkley RA, Edwards G, Laneri M, Fletcher K, Metevia L. Executive functioning, temporal discounting, and sense of time in adolescents with attention deficit hyperactivity disorder (ADHD) 
and oppositional defiant disorder (ODD). Journal of Abnormal Child Psychology. 2001; 29:541556. [PubMed: 11761287]

Barkley R, Fischer M, Smallish L, Fletcher K. The persistence of attention deficit hyperactivity disorder into young adulthood as a function of reporting source and definition of disorder. Journal of Abnormal Psychology. 2002; 111:279-289. [PubMed: 12003449]

Benjamini Y, Hochberg Y. Controlling the false discovery rate: a practical and powerful approach to multiple testing. Journal of the Royal Statistical Society. Series B (Methodological). 1995; 57:289_ 300 .

Benner AD, Graham S. The transition to high school as a developmental process among multiethnic urban youth. Child Development. 2009; 80:356-376. [PubMed: 19466997]

Bird HR, Gould MS, Staghezza B. Aggregating data from multiple informants in child psychiatry epidemiological research. Journal of the American Academy of Child \& Adolescent Psychiatry. 1992; 31(1):78-85. [PubMed: 1537785]

Brannan AM, Heflinger CA, Bickman L. The caregiver strain questionnaire measuring the impact on the family of living with a child with serious emotional disturbance. Journal of Emotional and Behavioral Disorders. 1997; 5:212-222.

Burke JD, Pardini DA, Loeber R. Reciprocal relationships between parenting behavior and disruptive psychopathology from childhood through adolescence. Journal of Abnormal Child Psychology. 2008; 36:679-692. [PubMed: 18286366]

Chronis AM, Lahey BB, Pelham WE Jr, Kipp HL, Baumann BL, Lee SS. Psychopathology and substance abuse in parents of young children with attention-deficit/hyperactivity disorder. Journal of the American Academy of Child and Adolescent Psychiatry. 2003; 42:1424-1432. [PubMed: 14627877]

Collins, LM., Lanza, ST. Latent class \& latent transition analysis: With applications in the social, behavioral, \& health sciences. Hoboken: Wiley; 2010.

Costello AB, Osborne JW. Best practices in exploratory factor analysis: four recommendations for getting the most from your analysis. Practical Assessment Research \& Evaluation. 2005; 7:1-9.

Darling N. Parenting style and its correlates. ERIC Digest. 1999

Derogatis, LR. SCL-90-R: Symptom Checklist-90-R: Administration, scoring, and procedures manual. Minneapolis: NCS Pearson; 1996.

Derogatis LR, Cleary PA. Confirmation of the dimensional structure of the SCL-90: a study in construct validation. Journal of Clinical Psychology. 1977; 33:981-989.

Eccles, J. Schools, academic motivation, and stage-environment fit. In: Lerner, R., Steinberg, L., editors. Handbook of adolescent psychology. 2nd. Hoboken: Wiley; 2004.

Eccles J, Harold R. Parent-school involvement during the early adolescent years. Teachers College Record. 1993; 94:568-587.

Escobar JI, Rubio-Stipec M, Canino G, Karno M. Somatic symptom index (SSI): a new and abridged somatization construct: prevalence and epidemiological correlates in two large community samples. The Journal of Nervous and Mental Disease. 1989; 177:140-146. [PubMed: 2918297]

Evans SW, Serpell ZN, Schultz BK, Pastor DA. Cumulative benefits of secondary school-based treatment of students with attention deficit hyperactivity disorder. School Psychology Review. 2007; 36:256-273.

Evans SW, Schultz BK, Demars CE, Davis H. Effectiveness of the challenging horizons program for young adolescents with ADHD. Behavior Therapy. 2011; 42:462-474. [PubMed: 21658528]

Fabiano GA, Pelham WE Jr, Waschbusch DA, Gnagy EM, Lahey BB, Chronis AM, Burrows-MacLean L. A practical measure of impairment: psychometric properties of the impairment rating scale in samples of children with attention deficit hyperactivity disorder and two school-based samples. Journal of Clinical Child and Adolescent Psychology. 2006; 35:369-385. [PubMed: 16836475]

Fan X, Chen M. Parental involvement and students' academic achievement: a meta-analysis. Educational Psychology Review. 2001; 13:1-22.

Fröjd SA, Nissinen ES, Pelkonen MU, Marttunen MJ, Koivisto AM, Kaltiala-Heino R. Depression and school performance in middle adolescent boys and girls. Journal of Adolescence. 2008; 31:485498. [PubMed: 17949806] 
Hill N, Tyson D. Parental involvement in middle school: a meta-analytic assessment of strategies that promote achievement. Developmental Psychology. 2009; 45:740-763. [PubMed: 19413429]

Hinshaw SP, Owens EB, Wells KC, Kraemer HC, Abikoff HB, Wigal T. Family processes and treatment outcome in the MTA: negative/ineffective parenting practices in relation to multimodal treatment. Journal of Abnormal Child Psychology. 2000; 28:555-568. [PubMed: 11104317]

Huber, PJ. Proceedings of the Fifth Berkeley Symposium on Mathematical Statistics and Probability. Vol. 1. Berkeley: University of California Press; 1967. The behavior of maximum likelihood estimates under nonstandard conditions; p. 221-233.

Jeynes WH. The relationship between parental involvement and urban secondary school student academic achievement a meta-analysis. Urban Education. 2007; 42:82-110.

Johnston C, Mash EJ. Families of children with attention-deficit/hyperactivity disorder: review and recommendations for future research. Clinical Child and Family Psychology Review. 2001; 4:183207. [PubMed: 11783738]

Kazdin, AE. Behavior modification in applied settings. 6th. Belmont: Wadsworth/Thomson Learning; 2001.

Kent KM, Pelham WE, Molina BSG, Sibley MH, Waschbusch DA, Yu J, Gnagy EM, Biswas A, Babinski DE, Karch KM. The academic experience of male high school students with ADHD. Journal of Abnormal Child Psychology. 2011; 39:451-462. [PubMed: 21103923]

Kuriyan AB, Pelham WE, Molina BSG, Daniel WA, Gnagy EM, Sibley MH, et al. Young adult educational and vocational outcomes of children diagnosed with ADHD. Journal of Abnormal Child Psychology. 2013; 41:27-41. [PubMed: 22752720]

Langberg JM, Epstein JN, Becker SP, Girio-Herrera E, Vaughn AJ. Evaluation of the homework, organization, and planning skills (HOPS) intervention for middle school students with attention deficit hyperactivity disorder as implemented by school mental health providers. School Psychology Review. 2012; 41:342-364. [PubMed: 25355991]

Langberg JM, Dvorsky MR, Evans SW. What specific facets of executive function are associated with academic functioning in youth with attention-deficit/hyperactivity disorder? Journal of Abnormal Child Psychology. 2013; 41:1145-1162. [PubMed: 23640285]

Mannuzza S, Klein RG, Moulton JL III. Lifetime criminality among boys with attention deficit hyperactivity disorder: a prospective follow-up study into adulthood using official arrest records. Psychiatry Research. 2008; 160:237-246. [PubMed: 18707766]

McCutcheon, AL., editor. Latent class analysis (no 64). Thousand Oaks: Sage; 1987.

Milich R, Balentine AC, Lynam DR. ADHD combined type and ADHD predominantly inattentive type are distinct and unrelated disorders. Clinical Psychology: Science and Practice. 2001; 8:463-488.

Molina BSG, Pelham WE, Cheong J, Marshal MP, Gnagy EM, Curran PJ. Childhood ADHD and growth in adolescent alcohol use: the roles of functional impairments, ADHD symptom persistence, and parental knowledge. Journal of Abnormal Psychology. 2012; 121:922-935. [PubMed: 22845650]

Murray C, Johnston C. Parenting in mothers with and without attention-deficit/hyperactivity disorder. Journal of Abnormal Psychology. 2006; 115:52. [PubMed: 16492095]

Múthen, LK., Múthen, BO. Mplus: Statistical analysis with latent variables. Los Angeles: Múthen \& Múthen; 1998-2010.

Nigg J, Blaskey L, Stawicki JA, Sachek J. Evaluating the endophenotype model of ADHD neuropsychological deficit: results for parents and siblings of children with ADHD combined and inattentive subtypes. Journal of Abnormal Psychology. 2004; 113:614. [PubMed: 15535793]

Pelham W, Gnagy E, Greenslade K, Milich R. Teacher ratings of DSM-III-R symptoms for the disruptive behavior disorders. Journal of the American Academy of Child and Adolescent Psychiatry. 1992; 31:210-218. [PubMed: 1564021]

Pelham WE, Fabiano GA, Massetti GM. Evidence-based assessment of attention deficit hyperactivity disorder in children and adolescents. Journal of Clinical Child and Adolescent Psychology. 2005; 34:449-476. [PubMed: 16026214]

Pomerantz EM, Moorman EA, Litwack SD. The how, whom, and why of parents' involvement in children's academic lives: more is not always better. Review of Educational Research. 2007; 77:373-410. 
Rogers MA, Wiener J, Marton I, Tannock R. Parental involvement in children's learning: comparing parents of children with and without attention-deficit/hyperactivity disorder (ADHD). Journal of School Psychology. 2009; 47:167-185. [PubMed: 19328285]

Rogers M, Hwang H, Toplak M, Weiss M, Tannock R. Inattention, working memory, and academic achievement in adolescents referred for attention deficit/hyperactivity disorder (ADHD). Child Neuropsychology. 2011; 17:444-458. [PubMed: 21390917]

Shaffer D, Fisher P, Lucas CP, Dulcan M, Schwab-Stone M. NIMH diagnostic interview schedule for children version IV (NIMH DISC-IV): description, differences from pervious versions, and reliability of some common diagnoses. Journal of the American Academy of Child and Adolescent Psychiatry. 2000; 39:28-38. [PubMed: 10638065]

Sibley MH, Pelham WE, Molina BSG, Gnagy EM, Waschbusch DA, Garefino A, Kuriyan AB, Babinski DE, Karch KM. Diagnosing ADHD in adolescence. Journal of Consulting and Clinical Psychology. 2012; 80:139-150. [PubMed: 22148878]

Sibley MH, Pelham WE, Derefinko KD, Kuriyan AB, Sanchez F, Graziano PA. A pilot trial of supporting teens' academic needs daily (STAND): a parent-adolescent collaborative intervention for ADHD. Journal of Psychopathology and Behavioral Assessment. 2013; 35:436-449.

Sibley MH, Altszuler AR, Morrow AS, Merrill BM. Mapping the academic problem behaviors of adolescents with ADHD. School Psychology Quarterly. 2014a; 29:422-437. [PubMed: 24933215]

Sibley MH, Altszuler AR, Ross JM, Sanchez F, Pelham WE, Gnagy EM. A group-based parent-teen collaborative intervention for high school students with ADHD. Cognitive and Behavioral Practice. 2014b; 21:32-42.

Sibley MH, Kuriyan AB, Evans SW, Waxmonsky JG, Smith BH. Pharmacological and psychosocial treatments for ADHD in adolescents: an updated systematic review of the literature. Clinical Psychology Review. 2014c; 34:218-232. [PubMed: 24632046]

Sibley, MH., Graziano, PA., Kuriyan, AB., Coxe, S., Pelham, WE. Parent-teen behavior therapy + motivational interviewing for adolescents with ADHD. In: Sibley (Chair), M., editor. Engaging Parents as a Mechanism of Youth Behavioral Change: Three Unique Interventions; Paper to be presented at the Biennial Meeting of the International Society for Research on Child and Adolescent Psychopathology; Portland, OR. 2015a.

Sibley, MH., Olson, SA., Morley, C., Pelham, WE. Are Consultation Models Appropriate for the School-Based Treatment of Adolescents with ADHD?. In: Sibley (Chair), M., editor. Enhancing Adult Implementation of Behavioral Interventions for ADHD: PersonLevel and Environmental Predictors; Paper to be presented at the Biennial Meeting of the International Society for Research on Child and Adolescent Psychopathology; Portland, OR. $2015 \mathrm{~b}$.

Steinberg L, Lamborn SD, Dornbusch SM, Darling N. Impact of parenting practices on adolescent achievement: authoritative parenting, school involvement, and encouragement to succeed. Child Development. 1992; 63:1266-1281. [PubMed: 1446552]

Unnever JD, Cullen FT, Pratt TC. Parental management, ADHD, and delinquent involvement: reassessing Gottfredson and Hirschi's general theory. Justice Quarterly. 2003; 20:471-500.

Velicer WF, Fava JL. Affects of variable and subject sampling on factor pattern recovery. Psychological Methods. 1998; 3:231.

Wechsler, D. Wechsler abbreviated scale of intelligence-II. San Antonio: Harcourt Assessment; $2011 \mathrm{a}$. Wechsler, D. Wechsler individual achievement tests-III. San Antonio: Harcourt Assessment; 2011 b.

White H. A heteroskedasticity-consistent covariance matrix estimator and a direct test for heteroskedasticity. Econometrica. 1980; 48:817-830. 


\section{Table 1}

Characteristics of the subsample

\begin{tabular}{|c|c|c|}
\hline & Middle School $(N=212)$ & High School $(N=87)$ \\
\hline Adolescent Age $M(S D)$ & $12.31(0.97)$ & $14.65(0.65)$ \\
\hline \multicolumn{3}{|l|}{ Adolescent Sex (\%) } \\
\hline Male & 66.5 & 79.3 \\
\hline Female & 33.5 & 20.7 \\
\hline \multicolumn{3}{|l|}{ Adolescent Race/Ethnicity (\%) } \\
\hline Non-Hispanic White & 7.7 & 9.3 \\
\hline Hispanic Any Race & 77.4 & 79.1 \\
\hline Black/African-American & 9.6 & 11.6 \\
\hline Other & 5.3 & 0.0 \\
\hline \multicolumn{3}{|l|}{ DSM-IV-TR ADHD Diagnosis (\%) } \\
\hline ADHD-PI & 37.7 & 42.5 \\
\hline ADHD-C & 61.8 & 56.3 \\
\hline ADHD-PH/I & 0.5 & 1.1 \\
\hline $\mathrm{LD}(\%)$ & 13.9 & 18.8 \\
\hline ODD $(\%)$ & 41.1 & 55.2 \\
\hline $\mathrm{CD}(\%)$ & 10.8 & 4.6 \\
\hline Affective Problems ${ }^{a}$ & 21.4 & 14.4 \\
\hline Anxiety Problems ${ }^{a}$ & 18.4 & 12.5 \\
\hline Current ADHD Medication (\%) & 41.0 & 37.9 \\
\hline Estimated Full Scale IQ & $98.13(12.23)$ & $94.84(12.13)$ \\
\hline Reading Achievement Standard Score & $101.29(12.47)$ & $94.75(14.41)$ \\
\hline Math Achievement Standard Score & $99.76(14.92)$ & $85.22(15.70)$ \\
\hline Grade Point Average & $2.15(0.75)$ & $2.08(0.70)$ \\
\hline \multicolumn{3}{|l|}{ Class Placement (\%) } \\
\hline Remedial/Self-Contained & 3.0 & 3.4 \\
\hline Some Regular/Some Remedial & 10.0 & 13.8 \\
\hline Regular/Inclusion & 73.5 & 69.0 \\
\hline Advanced/Gifted & 13.5 & 13.8 \\
\hline
\end{tabular}

Indicates T-score greater than 65 on the Youth Self Report (Achenbach 2009) 


\section{Table 2}

Characteristics of subsample parents

\begin{tabular}{ll}
\hline & $M(S D)$ \\
\hline Parent Age $M(S D)$ & $42.73(6.36)$ \\
Parent Relationship to Child & \\
$\quad$ Biological/Adoptive Mother & 83.2 \\
$\quad$ Biological/Adoptive Father & 14.8 \\
$\quad$ Stepfather & 0.7 \\
$\quad$ Grandmother & 1.3 \\
Parent Highest Parent Education Level & \\
$\quad$ High school or less & 25.4 \\
$\quad$ Some college or technical training & 23.6 \\
$\quad$ Bachelor's degree & 35.2 \\
$\quad$ Master's degree or higher & 15.8 \\
Single Parent (\%) & 36.1 \\
Number of Children $M(S D)$ & $2.66(1.27)$ \\
Parental ADHD Symptom Count M $(S D)$ & $2.76(3.60)$ \\
Parental Depression T-Score $M(S D)$ & $54.29(10.48)$ \\
Parental Anxiety T-Score $M(S D)$ & $49.31(9.48)$ \\
Parental Somatization T-Score $M(S D)$ & $51.34(10.38)$ \\
\hline
\end{tabular}

T-Scores for parental depression, anxiety, and somatization were available for 128 participants who were administered the SCL-90R 
Table 3

PAMS three-factor solution

\begin{tabular}{lllll}
\hline & $\mathbf{1}$ & $\mathbf{2}$ & \multicolumn{3}{l}{$\mathbf{3}$} \\
\hline Use an academic contract or daily rewards program & - & 0.82 & - \\
Communicate with your child's teachers & - & - & 0.48 \\
Help your child organize school materials & 0.74 & - & - \\
Check to see if your child wrote in a daily planner & 0.66 & - & - \\
Check the grade portal & - & 0.41 & 0.46 \\
Help your child plan out what to do during homework time & 0.80 & - & - \\
Help your child do his/her homework & 0.84 & - & - \\
Help your child study for an upcoming test & 0.71 & - & - \\
Check if your child had taken notes in class & 0.70 & - & - \\
Monitor if your child was studying or doing homework & 0.65 & - & - \\
Use a calendar to help your child plan for a long-term project & - & 0.57 & - \\
Check your child's homework for errors & 0.82 & - & - \\
Make a checklist or to-do list with your child & - & 0.66 & - \\
Provide a reward for completing academic tasks & - & -0.76 & - \\
Restrict privileges for failing to complete academic tasks & - & 0.52 & 0.41 \\
Do some of your child's homework for him/her & - & - & 0.76 \\
\hline
\end{tabular}




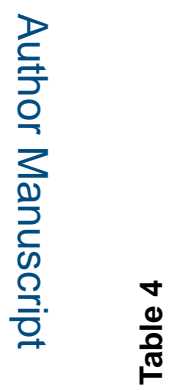

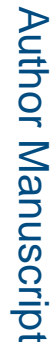

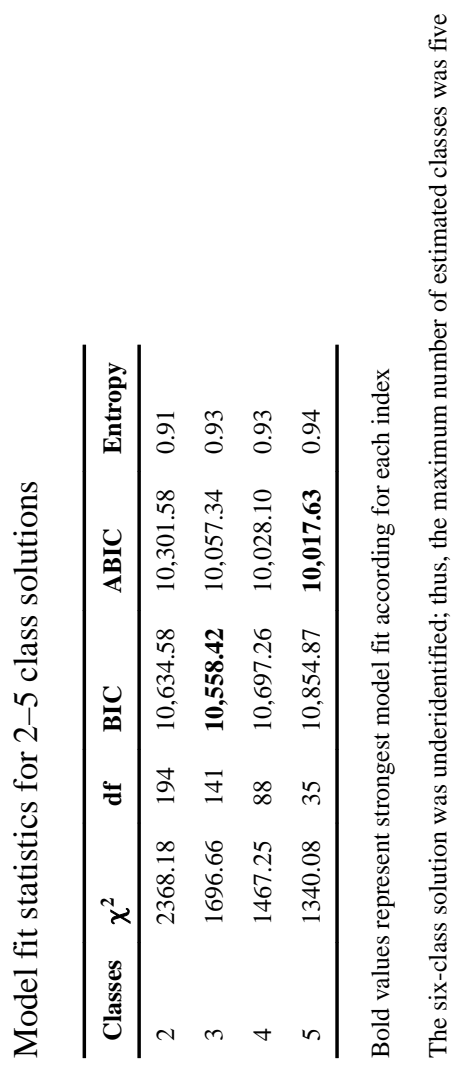

J Psychopathol Behav Assess. Author manuscript; available in PMC 2017 June 01. 
Table 5

Item response probabilities by latent class

\begin{tabular}{|c|c|c|c|c|}
\hline & 1 & 2 & 3 & 4 \\
\hline \multicolumn{5}{|c|}{ Use an academic contract or daily rewards program } \\
\hline Not at all & 0.495 & 0.265 & 0.800 & 0.865 \\
\hline At least 1 day a week & 0.505 & 0.735 & 0.200 & 0.135 \\
\hline \multicolumn{5}{|c|}{ Communicate with your child's teachers } \\
\hline Not at all & 0.036 & 0.119 & 0.217 & 0.397 \\
\hline $1-2$ days a week & 0.347 & 0.617 & 0.431 & 0.535 \\
\hline 3-4 days a week & 0.326 & 0.165 & 0.291 & 0.025 \\
\hline 5 days a week & 0.291 & 0.100 & 0.061 & 0.043 \\
\hline \multicolumn{5}{|c|}{ Help your child organize school materials } \\
\hline Not at all & 0.019 & 0.134 & 0.122 & 0.665 \\
\hline $1-2$ days a week & 0.070 & 0.457 & 0.451 & 0.305 \\
\hline 3-4 days a week & 0.195 & 0.317 & 0.291 & 0.000 \\
\hline 5 days a week & 0.716 & 0.093 & 0.078 & 0.030 \\
\hline \multicolumn{5}{|c|}{ Check to see if your child wrote in a daily planner } \\
\hline Not at all & 0.106 & 0.174 & 0.431 & 0.642 \\
\hline $1-2$ days a week & 0.088 & 0.383 & 0.158 & 0.230 \\
\hline 3-4 days a week & 0.129 & 0.226 & 0.266 & 0.083 \\
\hline 5 days a week & 0.678 & 0.216 & 0.144 & 0.044 \\
\hline \multicolumn{5}{|l|}{ Check the grade portal } \\
\hline Not at all & 0.019 & 0.048 & 0.233 & 0.440 \\
\hline $1-2$ days a week & 0.324 & 0.345 & 0.304 & 0.359 \\
\hline 3-4 days a week & 0.096 & 0.368 & 0.272 & 0.119 \\
\hline 5 days a week & 0.561 & 0.238 & 0.192 & 0.082 \\
\hline \multicolumn{5}{|c|}{ Help your child plan out what to do during homework time } \\
\hline Not at all & 0.018 & 0.153 & 0.247 & 0.575 \\
\hline $1-2$ days a week & 0.000 & 0.410 & 0.222 & 0.359 \\
\hline $3-4$ days a week & 0.146 & 0.403 & 0.369 & 0.054 \\
\hline 5 days a week & 0.836 & 0.034 & 0.161 & 0.039 \\
\hline \multicolumn{5}{|c|}{ Help your child do his/her homework } \\
\hline Not at all & 0.018 & 0.234 & 0.079 & 0.677 \\
\hline $1-2$ days a week & 0.054 & 0.612 & 0.227 & 0.316 \\
\hline 3-4 days a week & 0.148 & 0.154 & 0.572 & 0.000 \\
\hline 5 days a week & 0.781 & 0.000 & 0.121 & 0.007 \\
\hline \multicolumn{5}{|c|}{ Help your child study for an upcoming test } \\
\hline Not at all & 0.020 & 0.419 & 0.443 & 0.883 \\
\hline At least 1 day a week & 0.980 & 0.581 & 0.557 & 0.117 \\
\hline \multicolumn{5}{|c|}{ Check if your child had taken notes in class } \\
\hline Not at all & 0.086 & 0.366 & 0.560 & 0.790 \\
\hline At least 1 day a week & 0.914 & 0.634 & 0.440 & 0.210 \\
\hline
\end{tabular}

J Psychopathol Behav Assess. Author manuscript; available in PMC 2017 June 01. 


\begin{tabular}{|c|c|c|c|c|}
\hline & $\mathbf{1}$ & 2 & 3 & 4 \\
\hline \multicolumn{5}{|c|}{ Monitor if your child was studying or doing homework } \\
\hline Not at all & 0.000 & 0.052 & 0.051 & 0.209 \\
\hline At least 1 day a week & 1.000 & 0.948 & 0.949 & 0.791 \\
\hline \multicolumn{5}{|c|}{ Use a calendar to help your child plan for a long-term project } \\
\hline Not at all & 0.299 & 0.262 & 0.928 & 0.919 \\
\hline At least 1 day a week & 0.701 & 0.738 & 0.272 & 0.081 \\
\hline \multicolumn{5}{|c|}{ Check your child's homework for errors } \\
\hline Not at all & 0.035 & 0.185 & 0.214 & 0.708 \\
\hline $1-2$ days a week & 0.038 & 0.475 & 0.186 & 0.244 \\
\hline 3-4 days a week & 0.114 & 0.251 & 0.466 & 0.032 \\
\hline 5 days a week & 0.814 & 0.271 & 0.134 & 0.016 \\
\hline \multicolumn{5}{|c|}{ Make a checklist or to-do list with your child } \\
\hline Not at all & 0.412 & 0.244 & 0.877 & 0.939 \\
\hline At least 1 day a week & 0.588 & 0.756 & 0.123 & 0.061 \\
\hline \multicolumn{5}{|c|}{ Provide a reward for completing academic tasks } \\
\hline Not at all & 0.247 & 0.145 & 0.654 & 0.811 \\
\hline 1-2 days a week & 0.182 & 0.485 & 0.229 & 0.133 \\
\hline 3-4 days a week & 0.190 & 0.171 & 0.053 & 0.065 \\
\hline 5 days a week & 0.380 & 0.199 & 0.063 & 0.008 \\
\hline \multicolumn{5}{|c|}{ Restrict privileges for failing to complete academic tasks } \\
\hline Not at all & 0.089 & 0.182 & 0.275 & 0.544 \\
\hline 1-2 days a week & 0.254 & 0.276 & 0.402 & 0.327 \\
\hline 3-4 days a week & 0.180 & 0.300 & 0.169 & 0.060 \\
\hline 5 days a week & 0.477 & 0.243 & 0.154 & 0.069 \\
\hline \multicolumn{5}{|c|}{ Do some of your child's homework for him/her } \\
\hline Not at all & 0.678 & 0.745 & 0.562 & 0.982 \\
\hline At least 1 day a week & 0.322 & 0.255 & 0.438 & 0.018 \\
\hline
\end{tabular}

J Psychopathol Behav Assess. Author manuscript; available in PMC 2017 June 01. 


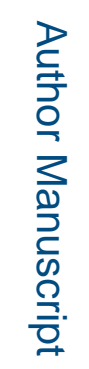

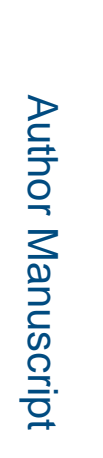

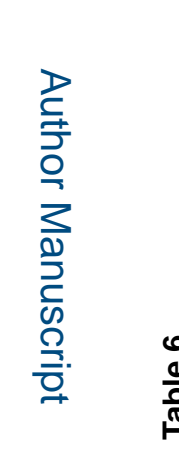

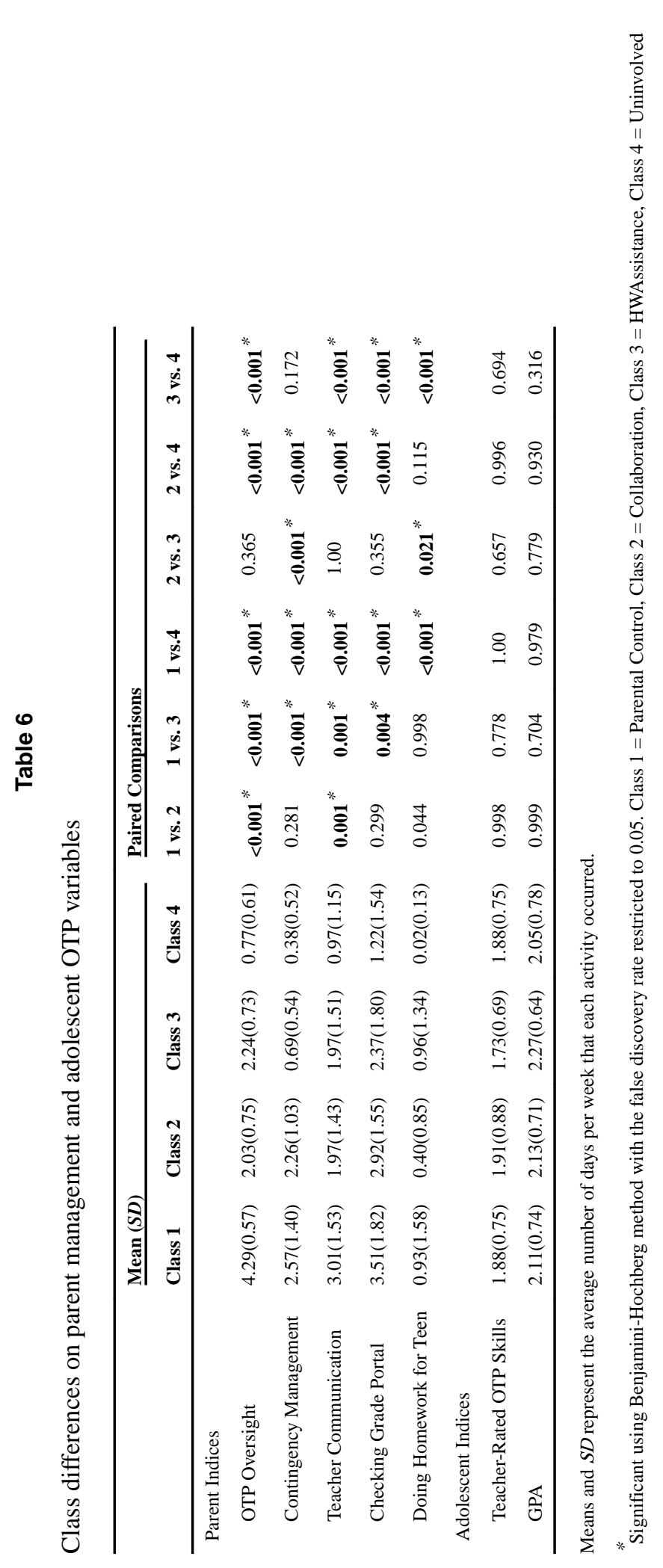

J Psychopathol Behav Assess. Author manuscript; available in PMC 2017 June 01. 


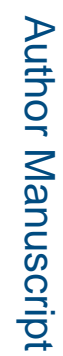

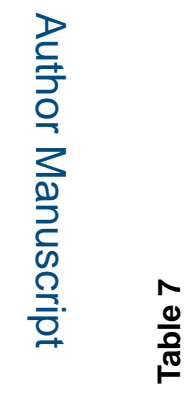

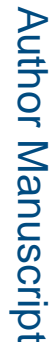

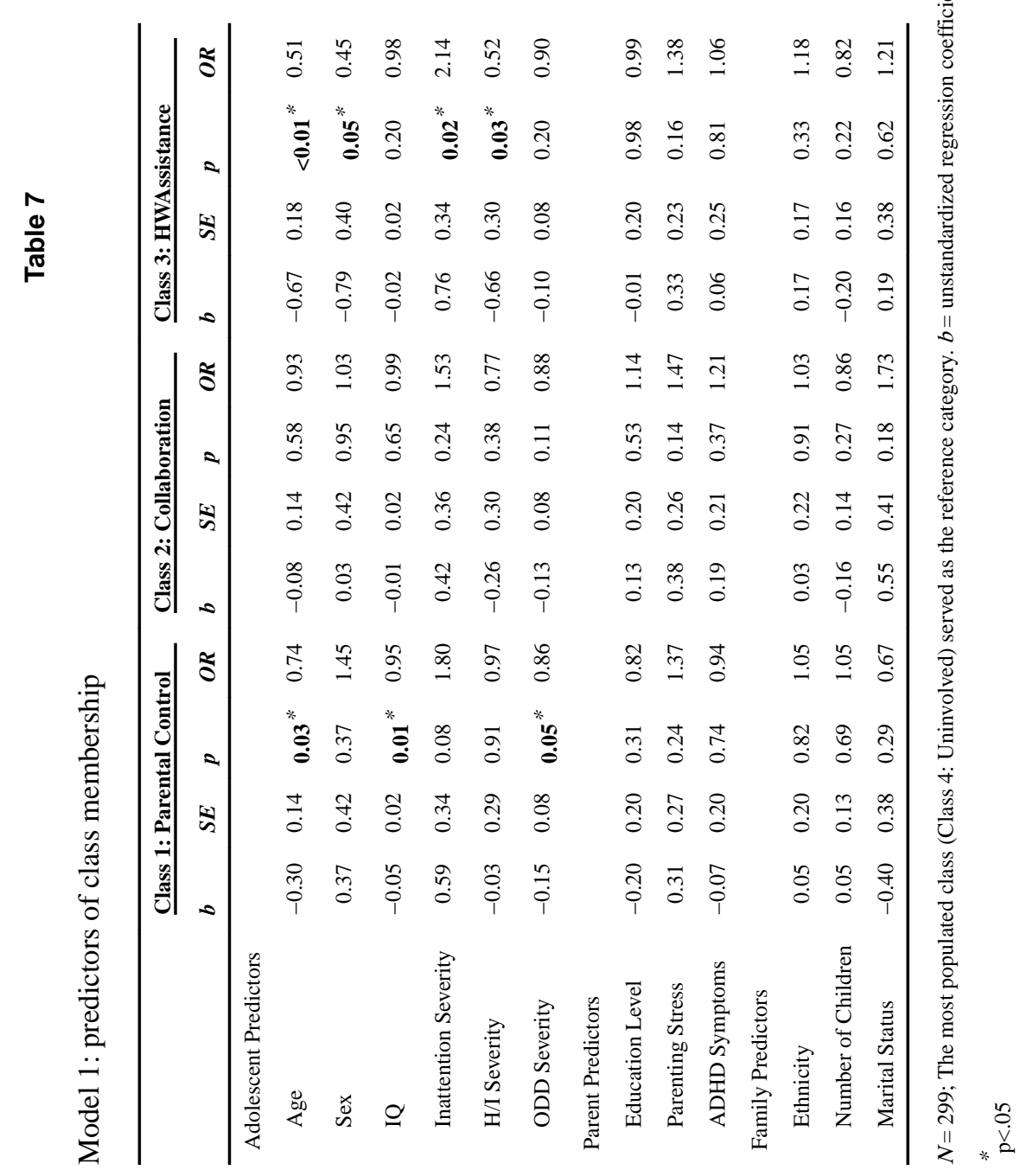

J Psychopathol Behav Assess. Author manuscript; available in PMC 2017 June 01. 


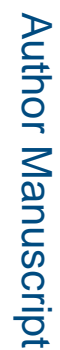

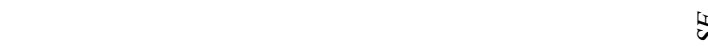

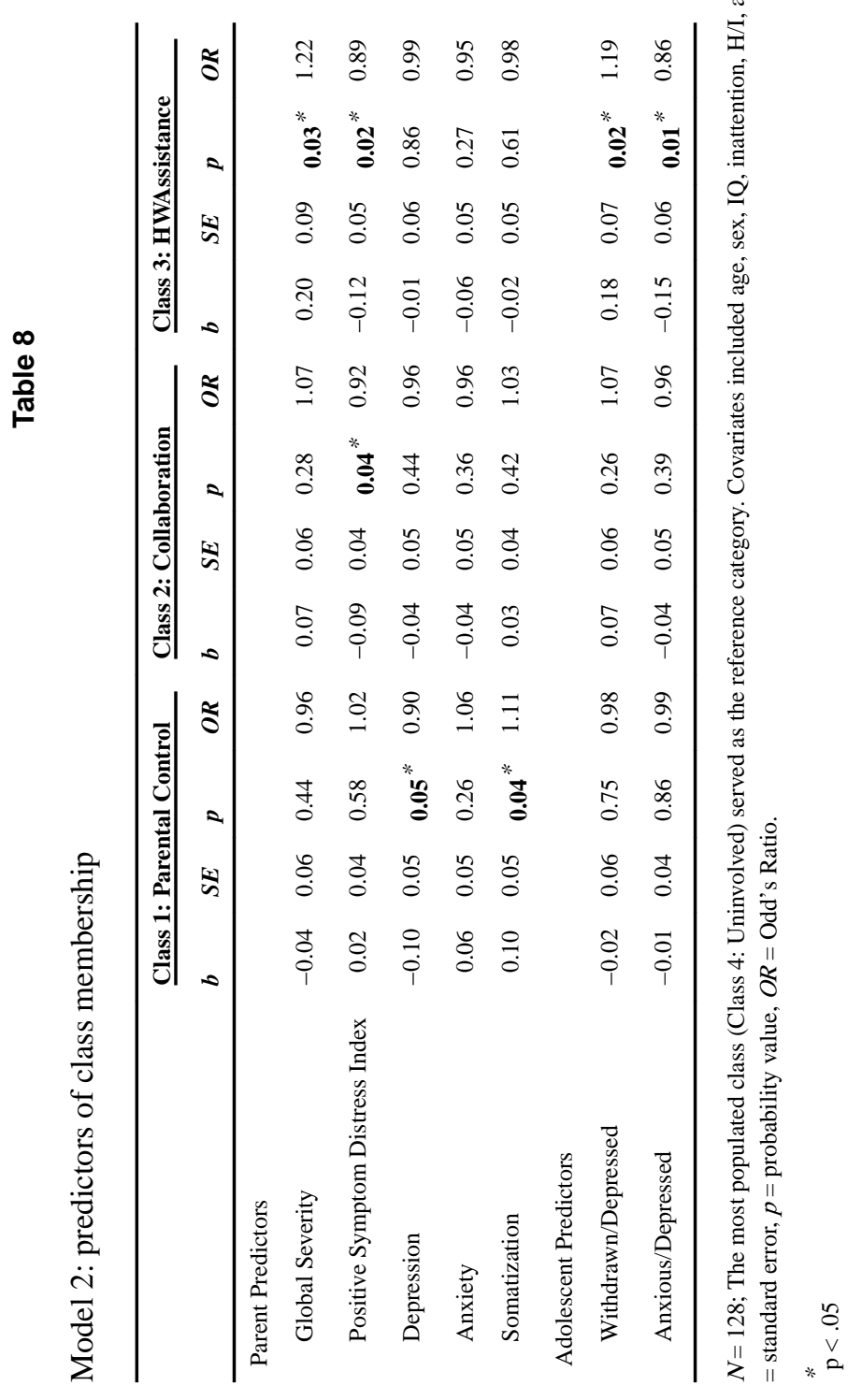

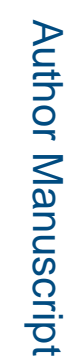

J Psychopathol Behav Assess. Author manuscript; available in PMC 2017 June 01. 